BLS 34, No 1 2008. DOI: http://dx.doi.org/10.3765/bls.v34i1.3563

(published by the Berkeley Linguistics Society and the Linguistic Society of America)

\title{
Perceptual Errors or Deliberate Avoidance? Types of English /r/- Dissimilation
}

\author{
NANCY HALL \\ California State University Long Beach
}

\section{Introduction}

American English avoids the presence of multiple $/ \mathrm{r} / \mathrm{s}$ in a word through several means. The purpose of this paper is to classify the types of $/ \mathrm{r} /$-dissimilation that exist in contemporary English, and to argue that these different types have different causes. Long-distance / $\mathrm{r}$-dissimilation is likely to result from perceptual errors rather than active avoidance of multiple $/ \mathrm{r} / \mathrm{s}$, but short-distance $/ \mathrm{r} /$ dissimilation is likely to reflect an active avoidance of $/ \mathrm{rVr} /$ sequences.

\section{Long-Distance /r/-Dissimilation}

\subsection{Dissimilatory Deletion}

The most common type of /r/-dissimilation in American English is the deletion of one $/ \mathrm{r} /$ in a word containing two or more $/ \mathrm{r} / \mathrm{s}$. This process was first extensively described by Hempl (1893), and remains common in modern American dialects. Some typical examples of this process are given below. The $/ \mathrm{r} /$ that has been reported as dropping is enclosed in parentheses. In some cases, dissimilation follows syncope of one vowel in a $/ \mathrm{VrV} /$ sequence; in these words, both the vowel and $/ \mathrm{r} /$ are parenthesized ${ }^{1}$.

$\begin{array}{ll} & \text { Sources }^{2} \\ \text { adve(r)sary } & \text { T1936 } \\ \text { Be(r)nard } & \text { KK1953, C2005 } \\ \text { afte(r)wards } & \text { H1893, T1936, KK1953, Y1983 }\end{array}$

\footnotetext{
For more extensive data, including additional published descriptions and new corpus and elicitation studies, see Hall (2008).

${ }^{2}$ Throughout this paper, the following sources are abbreviated in numbered examples by their authors' initials and years of publication: Canepari 2005, Hempl 1893, Kenyon \& Knott 1953, Merriam-Webster 1994, Randall 1988, Sherwood 1837, Thomas 1936, Yamada 1983. G2006 refers to the website http://www.barelybad.com/words1.htm\#rsareus. Thanks to the dozens of linguists who individually sent me examples; I have acknowledged by name those who contributed examples not found in any published source.
} 
Nancy Hall

ape(r)ture

be(r)serk

bomba(r)dier

Cante(r)bury

cate(r)pillar

cereb(r)al palsy

comfo(r)ter

easte(r)ner

elde(r)berry

ente(r)prise

ent(r)ep(r)eneur

forme(r)ly

furthe(r)more

gove(r)nor

hambu(r)ger

imp (r)opriety

inf(r)astructure

interp(r)et

lit(er)ature

northe(r)ner

ove(r)ture

paraphe(r)nalia

pa(r)ticular

pe(r)formance

pe(r)fumery

pre-p(r)ofessional

$p(r)$ ofessor

p(r)oportion

p(r)oprietor

repe(r)toire

rese(r)voir

resp(ir)atory

San Berna(r)dino

$\sec (r)$ etary

southe(r)ner

spect(r)ogram

stenog(r)apher

su(r)prise

su(r)veyor

synch(r)otron

temp(er)ature

the (r)mometer

ve(r)nacular

vet(er)inarian
Y1983

B. Vaux (p.c.)

R1988

KK1953, C2005

Y1983, R1988, M1994

J. Hall (p.c.)

H1893, KK1953, Y1983

KK1953

KK1953, M1994, C2005

H1893, KK1953

G2006 [either $/ \mathrm{r} /$ could delete]

H1893, KK1953

KK1953, Y1983

T1936, KK1953, M1994

B. Erickson, B. Vaux (p.c.)

KK1953, Y1983

G2006

KK1953

G2006

H1893, T1936, KK1953, C2005

Y1983

KK1953, M1994

H1893, T1936, KK1953, Y1983

H1893, T1936, KK1953, Y 1983

H1893, KK1953, Y1983

KK1953

T1936, C2005

KK1953, Y1983

KK1953

G2006, D. Kamholz (p.c.)

KK1953, C2005

Y1983, G2006

KK1953

KK1953, Y1983, C2005

KK1953, C2005

author's observation

C2005

H1893, T1936, KK1953, Y1983, M1994, R1988

KK1953, Y1983

M1994

T1936, Y1983

H1893, T1936, KK1953, Y1983, M1994

KK1953, Y1983, M1994

G2006

134 


\section{Perceptual Errors or Deliberate Avoidance?}

For the words above, the dissimilated pronunciations are never obligatory, but in some words, such as berserk and surprise, the dissimilated version is the most common pronunciation. In general, $/ \mathrm{r} /$-dissimilation of this type is little stigmatized, except when it involves deletion of a stressed onset /r/, as in lib(r)ary, lib(r)arian, or $f(r)$ ustrated. Each of these pronunciations is considered uneducated. For most items, speakers tend to be aware that the /r/ exists even if they do not pronounce it; but for a few items such as barbiturate and paraphernalia, many speakers are not aware of the second $/ \mathrm{r} /$ and omit it in spelling. There are a few other words in which a historical $/ \mathrm{r} /$ has been permanently dropped: the city once called Alburquerque is now officially Albuquerque, and the term cater-cornered seems to have been replaced by catty-corner.

It is not fully predictable which words will undergo dissimilation and which will not, and there appear to be significant differences between different dialects of American English in this respect, as well as difference between individuals. However, there are some noticeable trends in the process. In most dialects, only a completely unstressed $/ \mathrm{r} /$ deletes through dissimilation. Some dialects additionally delete coda $/ \mathrm{r} /$ in stressed syllables, in words like co(r)ner or fo(r)ward. Usually it is the first of the two $/ \mathrm{r} / \mathrm{s}$ in the word that deletes (although there are a few common exceptions, like paraphe(r)nalia.) Dissimilation never deletes a word-initial or word-final $/ \mathrm{r} /$. It is very commonly triggered by a word-final $/ \mathrm{r} /$, but rarely by a word-initial $/ \mathrm{r} /$. Dissimilation may occasionally operate across word boundaries within common collocations like wa(r)m weather (Hempl 1893) and more o(r) less (Kenyon \& Knott 1953), but does not work productively across word boundaries in new collocations.

\subsection{Long-Distance Dissimilation through Sound Substitution}

There are a smaller number of words in which one of two /r/s changes to another sonorant, as shown below.

\begin{tabular}{|c|c|c|c|}
\hline $\mathrm{r} \rightarrow \mathrm{j}$ & $\begin{array}{l}\text { defibrillator } \\
\text { February }\end{array}$ & $\begin{array}{l}\text { difibjaleır } \\
\text { febjueri }\end{array}$ & $\begin{array}{l}\text { G2006, B. Kennedy } \\
\text { S1837, H1893, G2006 }\end{array}$ \\
\hline $\mathrm{r} \rightarrow 1$ & $\begin{array}{l}\text { frustrated } \\
\text { fritters }\end{array}$ & $\begin{array}{l}\text { fl } \Lambda \text { stre Ir Id } \\
\text { flis }{ }^{\prime} \mathrm{z}\end{array}$ & $\begin{array}{l}\text { S1837 } \\
\text { S1837 }\end{array}$ \\
\hline $\mathrm{r} \rightarrow \mathrm{n}$ & Purmort & proment & H1893 \\
\hline
\end{tabular}

However, dissimilation through segment substitution is rare compared to dissimilation through deletion. As seen by the dates on the references above, most examples of this process are very old and may reflect much earlier stages of the development of English. 
Nancy Hall

\section{A Perceptual Account of Long-Distance/r/-Dissimilation}

Ohala (1981) proposes that dissimilation, as a diachronic change, is a result of perceptual hypercorrection for phonetic assimilation. Speakers coarticulate speech segments, so that each segment is affected by the segments before and after it. A sequence $/ \mathrm{np} /$, for example, is likely to sound similar to [mp] due to anticipatory coarticulation of the nasal with the labial stop. Listeners are required to compensate for this coarticulation in order to correctly decipher the intended string of phonemes. Ohala points out that a listener could make at least two possible errors. One error would be to underestimate the extent of coarticulation, thinking that a phonetic [mp] from $/ \mathrm{np} /$ is actually intended as $/ \mathrm{mp} /$. This error would result in the listener learning an assimilated form of the sequence. Another possible error is to overestimate the extent of coarticulation, and hence factor out perceived coarticulation where there was none. In this case, the listener would mistakenly believe that two sounds with identical features, such as [mp], were intended to have different features, such as $/ \mathrm{np} /$. The listener would therefore internalize a dissimilated representation.

It is plausible that long-distance / $\mathrm{r}$-dissimilation could occur this way, because liquids, including $/ \mathrm{r} /$, are known to have long-range acoustic effects. These effects, often called "resonances" (Kelly \& Local 1986) have been documented for several British dialects (the relevant experiments have not yet been carried out on American dialects). Tunley (1999) shows that that an /1/ raises the F2 and F3 of nearby high vowels, relative to a neutral $/ \mathrm{h} /$, while $/ \mathrm{r} /$ lowers the $\mathrm{F} 2$ and $\mathrm{F} 3$ of the vowels, two syllables in each direction. West (1999a) gives articulatory evidence that the articulation of $/ \mathrm{r} /$ is spread over several syllables: her EPG and EMA study finds lower F3, more lip rounding, and the tongue higher and backer preceding $/ r /$ than $/ 1 /$. Heid \& Hawkins (2000) find acoustic effects of $/ r /$ as far as five syllables in advance of the $/ \mathrm{r} /$ itself.

These long-range resonances could cause one $/ \mathrm{r} /$ to mask the presence of another in the same word. In a word like surprise, the rhoticity of the first vowel could be mistakenly attributed to anticipatory effects of the second / $\mathrm{r} /$, so that the listener believes that /səpraiz/ was intended. Although experimental work is needed to confirm that such errors are possible, the data on long-distance / $\mathrm{r} /$ dissimilation seem consistent with the perceptual theory. This theory explains why it is $/ \mathrm{r} /$ and not some other consonant that undergoes long-distance dissimilation: /r/ has long-range acoustic effects, which most consonants do not. ${ }^{3}$ The perceptual theory can also explain why this dissimilation is primarily anticipatory. There is some indication that $/ \mathrm{r} /$ has a stronger effect on preceding than following vowels: West (1999b:419) found 'robust anticipatory, not perseverative, resonance distinctions'. Thus, it is more likely that a later $/ \mathrm{r} /$ would mask an earlier $/ \mathrm{r} /$ than vice versa. It is also unsurprising under the perceptual theory that wordinitial and word-final $/ \mathrm{r} /$ do not delete. These positions are perceptually priveleged

\footnotetext{
${ }^{3}$ The sound /1/ also has long-range resonances, and /1...1/ sequences may dissimilate as well, in words like $f u(l) f i l l$, ophtha(l)mologist, and Pache(l)bel.
} 


\section{Perceptual Errors or Deliberate Avoidance?}

and an $/ \mathrm{r} /$ in such a position is unlikely to be mistaken for a [ə]. It is also unsurprising that unstressed / $\mathrm{r} /$ (especially /or/, which is acoustically realized as [r]) would undergo dissimilation more often than stressed $/ \mathrm{r} /$ : again, unstressed material is less perceptually prominent.

\section{Assimilatory / $\mathbf{r} /$-Insertion}

Another prediction of the perceptual account is that perceptual errors should be possible in two directions. The resonances of one $/ \mathrm{r} /$ may mask the presence of an earlier $/ \mathrm{r} /$; but a listener could also make the opposite mistake of interpreting the resonances of one $/ \mathrm{r} /$ as the presence of a second $/ \mathrm{r} /$. Hence, $/ \mathrm{r} /$ should sometimes be inserted in the same sorts of environments where it typically deletes. This does in fact occur: in a number of words that standardly contain one $/ \mathrm{r} /$, it is common to hear speakers insert a second $/ \mathrm{r}$, , usually earlier in the word, as in the examples below.

\begin{tabular}{|c|c|c|}
\hline familiar & farmiljər & S1837, T1936 \\
\hline persevere & prsa'vir & E1999, G2006 \\
\hline photographer & fərtagð口fa & G2006, R. Sittler (p.c.) \\
\hline pejorative & prdzorətiv & G2006 \\
\hline lavatory & lævətori & J. Kammert (p.c.) \\
\hline integral & Intžgral & G2006, P. Brians \\
\hline
\end{tabular}

If long-distance $/ \mathrm{r}$-dissimilation were motivated by a desire to avoid the presence of two $/ \mathrm{r} / \mathrm{s}$ in a word, then this type of $/ \mathrm{r} /$-insertion would seem unmotivated. However, it can be explained neatly under the perceptual account: rhotic resonances color an earlier $/ \mathrm{a} /$ to the point that it sounds like $\left[{ }^{\gamma}\right]$, and hence is internalized by some listeners as containing a second rhotic.

\section{Non-Perceptual Causes of Dissimilation}

The question of whether dissimilation is caused by perceptual errors is controversial. Another cause of dissimilation could be deliberate avoidance of multiple $/ \mathrm{r} / \mathrm{s}$ in a word, caused by a grammatical constraint against such a structure. The grammatical constraint could be grounded in the articulatory difficulty of repeated sounds, or in processing constraints on repeated elements (Frisch 2004).

To show why this is not the most likely cause of American long-distance /r/dissimilation, I will contrast this process with another dissimilatory phenomenon in English: the avoidance of /ror/. This sequence is removed or avoided through diverse methods, some of which are clearly deliberate and not explainable as misperception. Some of these methods could in principle also be used to achieve long-distance $/ \mathrm{r} /$-dissimilation, but they are not. This suggests that long-distance and short-distance $/ \mathrm{r}$-dissimilation are distinct phenomena. The fact that known methods of deliberate short-distance dissimilation are not extended to longdistance dissimilation suggests that speakers do not deliberately avoid the presence of multiple $/ \mathrm{r} / \mathrm{s}$ separated by more than a vowel. 


\section{Nancy Hall}

\section{Short-Distance [r]-Dissimilation}

\subsection{Avoidance of $\mathrm{rVr}$ through Deletion}

The sequence of $/ \mathrm{rVr} /$ (where $\mathrm{V}$ is a vowel), and especially /rər/ (phonetically $\left[\mathrm{rr}^{\mathrm{r}}\right]$ ), is avoided through a number of means in English. In words that have /rər/ in medial position, it is common for one of the $/ \mathrm{r} / \mathrm{s}$ to delete. In the examples below, we see that the $/ \mathrm{r} /$ that deletes is the one that is adjacent to a consonant.

$$
\begin{aligned}
& \text { inf(r)ared } \\
& p(r) \text { erogative } \\
& \text { Ghira }(r) \text { delli } \\
& \text { Garra(r)d }
\end{aligned}
$$

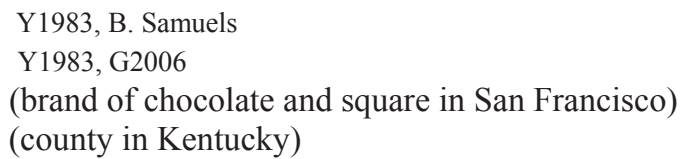

Such deletion is largely confined to /ror/, but occasionally occurs with other $/ \mathrm{rVr}$ / sequences as well. The Burberry clothing line Prorsum is reportedly pronounced [porsəm] by rhotic speakers, and loss of the first $/ \mathrm{r} /$ in lib(r)ary is a well-known shibboleth. Some speakers also drop the second $/ \mathrm{r} /$ in rural.

In final position, it is common for /rər/ to reduce to [r], especially in the word mirror and other monomorphemes. Such reduction seems less common when the final/or/ is a suffix, in words like hearer.

$\begin{array}{ll}\text { mirr(or) } & \text { mir } \\ \text { err(or) } & \varepsilon \mathrm{r} \\ \text { terr }(\text { or }) & \text { ter } \\ \text { jur }(\text { or }) & \mathrm{d} z \mathrm{ur} \sim \mathrm{d}_{3}{ }^{\circ}\end{array}$

This type of reduction is somewhat stigmatized. For example, the prescriptivist Elster (1999:257) writes: 'Mirror has two syllables. Avoid the pronunciation of the slovenly speaker who says MEER, like the word mere, and the illiterate speaker who says MUR'.

Some speakers, perhaps in reaction to such stigmatization, avoid /rər/ in the words above through the opposite tack of changing the schwa to a full vowel, [o]. This pronunciation seems more acceptable, and is even associated with particularly educated speakers.

$\begin{array}{ll}\text { 'Overpronunciation' of /ror/ } \\ \text { error } & \text { Eror } \\ \text { juror } & \text { dzuror }\end{array}$

Speakers of some American dialects may also drop only the final $/ \mathrm{r} /$ in words like mirror. I have heard the pronunciation [mirə] from some otherwise highly rhotic Arkansas speakers.

The cause of these reductions is debatable, but they could well result from the difficulty of perceiving / $\mathrm{r} ə \mathrm{r} /$, which is typically produced as [rər]. On spectrograms, the difference between words like mere and mirror appears to be primarily 


\section{Perceptual Errors or Deliberate Avoidance?}

in the length of the final rhotic section: both words have a period of low F3 values at the end, but for mirror it is longer than for mere. In fast speech, it might be difficult to accurately judge the intended length, and hence possible to mistake final $[\mathrm{rr}]$ for $[\mathrm{r}]$.

\subsection{Avoidance of / $\mathrm{r}$ r/ through Morphological Means}

Since English has several affixes and clitics containing $/ \mathrm{r} /$, there are ways that /rər/ can be avoided through morphological choices or morphological haplology.

In forming adjectival comparatives, there is a choice between using the suffix -er as in prettier or the separate word more as in more pretty. Typically monosyllables take the suffix -er. Yet Mondorf (1993), in a corpus study of comparatives in writing, shows that monosyllables ending in $/ \mathrm{r} /$ are suffixed less often than other monosyllables, making words like barer, sourer, clearer, dearer, purer, rarer, and surer less common than would be expected, in favor of more bare, more clear, etc. The effect is gradient, not absolute; all of the -er forms above are acceptable (although many speakers find sourer hard to pronounce).

Another morphological effect that may be related to /ror/ avoidance is the avoidance of the contracted form where're. Dixon (1982) notes that some speakers seem to contract where is not to where're, but to where's, as in (b) below. This apparent number mismatch between the copula and following noun phrase is possible only when the copula is contracted, and only when the contracted copula directly follows where: in other words, only where a /rər/ sequence would otherwise result.
a. Where are the lions?
Where're the lions?
b. *Where is the lions?
Where's the lions?
c. Where the hell are the lions?
Where the hell're the lions?
d. *Where the hell is the lions?
*Where the hell's the lions?

Dixon argues that this pattern "is undoubtedly due to a desire to avoid the infelicitous phonological sequence where're." This conclusion is controversial; Nathan (1981), for example, points out that the pattern is limited by complex syntactic restrictions and concludes that "it is certainly no longer a purely phonological phenomenon, if it ever was." Nevertheless, it is possible that the phonological badness of /rər/ was one of the factors originally stimulating the expanded use of where's, even if the pattern has since become grammaticized in a way that is more syntactic than phonological. ${ }^{4}$

Another morpheme that seems to be blocked after $/ \mathrm{r} /$ is the derivational suffix -ery. This suffix creates a noun, often meaning a profession or workplace. Although the CELEX database (Baayan et al. 1995) contains 96 examples of monosyllables taking this suffix, in none of these does the suffix -ery attach to a base

\footnotetext{
${ }^{4}$ Thanks to Matt Wolf for bringing this pattern to my attention.
} 


\section{Nancy Hall}

ending in $/ \mathrm{r} /$. The examples below contrast monosyllables that do take -ery with semantically similar monosyllables ending in $/ \mathrm{r} /$ that do not take -ery.

$\begin{array}{ll}\text { Avoidance of -ery after /r/ } & \\ \text { winery } & \text { ?beerery } \\ \text { mockery, railery } & * \text { jeerery, *heerery, *leerery } \\ \text { thievery, thuggery, foolery, roguery, } & \text { ? whorery, *boorery } \\ \text { knavery, witchery } & \\ \text { piggery } & * \text { boarery } \\ \text { machinery } & * \text { gearery, }{ }^{*} \text { wirery } \\ \text { deanery, popery } & * \text { czarery } \\ \text { Hair Cuttery } & * \text { shearery }\end{array}$

A second factory preventing -rery from surfacing is an apparent morphological haplology. There are a large number of cases where -ery is added to a base or two or more syllables ending in /ər/, but the expected sequence /ərəri/ does not result: instead, the sequence reduces to /ori/, as pointed out by Dressler (1977).

$$
\text { confection confectioner confectionery }
$$

BUT:

$\begin{array}{lll}\text { slaughter } & \text { slaughterer } & \text { slaughtery } \\ \text { embroider } & \text { *mbroiderer } & \text { *mbroidery } \\ \text { soldier } & \text { soldiery } \\ \text { upholster } & \text { upholsterer } & \text { upholstery }\end{array}$

While /ror/ is sometimes avoided through morphological means, it is not always avoided. The agentive suffix -er seems to have an unrestricted ability to combine with /r/-final verbs, producing nouns such as perjurer, caterer, loiterer, etc. Perhaps this common suffix is simply too useful to restrict.

\subsection{Avoidance of / ror/ through Blocking of $/ \mathbf{r} /$-Insertion}

Various English dialects have processes that insert $/ \mathrm{r} /$ in various environments. This section reviews three cases where such insertion is blocked by a nearby $/ \mathrm{r} /$.

Some non-standard dialects of English insert $/ \mathrm{r} /$ after final /o/, especially in words with an orthographic -o or -ow, so that a word like yellow is pronounced [jहlə]. This $/ \mathrm{r} /$ insertion is commonly (although not universally) blocked in words ending in /ro/. For example, in the Great Smoky Mountain dialect (Hall 1942), /r/insertion applies to the words in (a) but not those in (b), which are pronounced with final [ə].

(10) /r/-insertion: banjo, mosquito, piano, potato, tobacco, tomato, fellow, follow, hollow, meadow, mellow, pillow, shadow, shallow, tallow, wallow, widow, window, yellow 
no /r/-insertion: furrow, harrow, narrow, sparrow, tomorrow, wheelbarrow, Dillsboro, Middlesboro.

Shores (2000) reports a similar pattern in Tangier Island, Virginia, with the twist that words historically ending in /rə/ may be pronounced with final [ə], [i], or no vowel at all, as shown below.

$\begin{array}{ll}\text { wheelbarrow } & \text { wilbærə } \sim \text { wilbær } \\ \text { tomorrow } & \text { təmarə } \sim \text { təmar } \\ \text { borrow } & \text { bari }\end{array}$

Another type of $/ \mathrm{r}$--insertion occurs in non-rhotic dialects, where $/ \mathrm{r} /$ is pronounced only before vowels. In these dialects, a word-final $/ \mathrm{r} /$ is pronounced only if the next word begins with a vowel ("linking / $\mathrm{r} /$ ", as in (a) below), and an "intrusive / $\mathrm{r}$ " " may be inserted when a vowel-final word precedes a word beginning with a vowel, as in (b). However, some British speakers report that linking and intrusive $/ \mathrm{r} /$ are avoided after words ending in $/ \mathrm{rV} /$ as in (c) and (d), where their presence would create an $/ \mathrm{rVr} /$ sequence (Wyn Johnson, p.c.).

\begin{tabular}{|c|c|c|}
\hline & Linking [r]: & Intrusive $[\mathrm{r}]$ : \\
\hline$/ \mathrm{r} /$ present: & a. a river of it & Rita $\underline{r}$ is \\
\hline$/ \mathrm{r} / \mathrm{abse}$ & $\begin{array}{l}\text { pour a glass } \\
\text { an error in it } \\
\text { a roar of laughter }\end{array}$ & $\begin{array}{l}\text { law } \underline{r} \text { and order } \\
\text { Farrah is } \\
\text { raw apples }\end{array}$ \\
\hline
\end{tabular}

I do not know whether this pattern exists in any non-rhotic American dialects; John McCarthy (p.c.) reports that the blocking does not seem to occur in his native Boston dialect.

One more type of $/ \mathrm{r}$ /-insertion which may be blocked due to avoidance of $\mathrm{rVr} /$ is warsh-type insertion. Many Americans insert an /r/ into /af/ or /of/ sequences, in words like wash, squash, gosh (Gick 1999:33) and mosh (Eggcorn Database, http://eggcorns.lascribe.net). I have not heard / $\mathrm{r} /$ inserted in frosh (slang for freshman), or rosh hashana, where it would create an /rar/ or /ror/ sequence.

\subsection{Avoidance of $/ \mathbf{r V r} /$ in Naming Choices}

Martin (2007) shows that identical liquids separated by a vowel are statistically underrepresented (compared to non-identical liquids separated by vowels) in popular baby names, product names, and names chosen by participants in fantasy role-playing games. Since name choice is one of the few situations in which speakers get to choose between a wide range of phonological forms, it provides an additional piece of evidence that $/ \mathrm{rVr} /$ (as well as $/ \mathrm{lVl} /$ ) is dispreferred. 


\section{Nancy Hall}

\section{Causes of Short-Distance Dissimilation}

We have seen that /ror/, and to some extent $/ \mathrm{rVr} /$ more generally, are avoided through a great variety of means. Although most of these means are gradient rather than absolute, together they strongly suggest that /ror/ is dispreferred in English phonology. Furthermore, several of the methods of /ror/ avoidance described above cannot be attributed to misperception, and clearly involve some level of deliberate avoidance. The morphological choice of more sour over sourer must be purposeful; it is implausible that anyone mishears one as the other. Misperception could not explain why speakers don't add the suffix -ery to bases ending in $/ \mathrm{r} /$, or why they substitute where's for where're, or why they avoid $/ \mathrm{rVr} /$ when choosing names. I conclude that some if not all of the /rər/ avoidance methods discussed above are active, deliberate strategies, rather than being a result of misperceptions.

Interestingly, none of these deliberate methods are used to achieve longdistance dissimilation, although several in principle could be. Whereas -ery does not attach to /r/-final bases, it does attach to bases containing a non-final $/ \mathrm{r} /$, producing words like trickery and rockery. In Tangier Island, final $/ \mathrm{r} /$-insertion does not apply where it would create /rər/, but it does apply in at least one word with an earlier /r/, Bristow. While comparatives containing /rər/ like sourer are dispreferred, comparatives like brighter and redder, which contain two $/ \mathrm{r} / \mathrm{s}$ separated by several segments, seem perfectly acceptable. Intrusive and linking /r/ are not blocked by an $/ \mathrm{r} /$ earlier in the word either. I do not know whether liquids separated by more than a vowel are dispreferred in name choice.

\section{Conclusion}

I propose that the best way to make sense of this difference between long and short-distance / $/ \mathrm{r}$-dissimilation is to conjecture that they have different causes. Long-distance $/ \mathrm{r}$-dissimilation is not actively favored by the phonological grammar; it happens to occur sometimes when words are imperfectly transmitted from speaker to speaker due to misperceptions caused by the spread-out acoustic qualities of $/ \mathrm{r} /$. The same acoustic ambiguity also causes the opposite process of assimilatory / $\mathrm{r}$-insertion. Short-distance / $\mathrm{r} /$-dissimilation, on the other hand, is actively favored by the grammar, and almost all available means of avoiding /ror/ are employed to some extent. There seem to be no opposing processes that would favor creating /rər/ sequences.

\section{References}

Baayan, R. H., R. Piepenbrock and L. Gulikers. 1995. The CELEX Lexical Database (CD-ROM).

Canepari, Luciano. 2005. A Handbook of Pronunciation. München: Lincom Europa. 
Dixon, R. M. W. 1982. Where Have All the Adjectives Gone? and Other Essays in Semantics and Syntax. Berlin: Mouton.

Dressler, Wolfgang U. 1977. Phono-morphological Dissimilation. In Phonologica 1976, 41-8.

Elster, Charles Harrington. 1999. The Big Book of Beastly Mispronunciations: The Complete Opinionated Guide for the Careful Speaker. Boston: Houghton Mifflin Company.

Frisch, Stefan A. 2004. Language Processing and OCP effects. In Bruce Hayes, Robert Kirchner and Donca Steriade, eds., Phonetically-based Phonology, 346-371. Cambridge: Cambridge University Press.

Gick, Bryan. 1999. A Gesture-Based Account of Intrusive Consonants in English. Phonology 16:29-54.

Hall, Joseph Sargent. 1942. The Phonetics of Great Smoky Mountain Speech. New York: King's Crown Press.

Hall, Nancy. 2008. R-Dissimilation in American English. Unpublished manuscript.

Heid, Sebastian and Sarah Hawkins. 2000. An Acoustical Study of Long Domain $/ \mathrm{r} /$ and /1/ Coarticulation. In Proceedings of the Fifth Seminar on Speech Production: Models and Data, 77-80. Kloster Seeon, Bavaria, Germany.

Hempl, George. 1893. Loss of $\mathrm{r}$ in English through Dissimilation. Dialect Notes $1: 279-81$.

Kelly, J. and J. K. Local. 1986. Long-Domain Resonance Patterns in English. In International Conference on Speech Input/Output; Techniques and Applications. London: Institute of Electrical Engineers, 304-309. Conference Publication no. 258, 56-59.

Kenyon, John Samuel and Thomas Albert Knott. 1953. A Pronouncing Dictionary of American English. Springfield, Mass.: Merriam-Webster.

Martin, Andrew. 2007. The Evolving Lexicon. Ph.D. diss., University of California, Los Angeles.

Merriam-Webster, Inc. 1994. Merriam-Webster's Dictionary of English Usage. USA: Merriam-Webster.

Mondorf, Britta. 1993. Support for More-Support. In Determinants of Grammatical Variation in English, no. 43 in Topics in English Linguistics, 251-304. Berlin: Mouton de Gruyter.

Nathan, Geoffrey S. 1981. What's These Facts About? Linguistic Inquiry 12:151153.

Ohala, John J. 1981. The Listener as a Source of Sound Change. In Papers from the Parasession on Language and Behavior, 251-274. Chicago: Chicago Linguistics Society.

Randall, Bernice. 1988. Webster's New World Guide to Current American Usage. New York: Webster's New World.

Sherwood, Adiel. 1837. A Gazetteer of the State of Georgia: Embracing a Particular Description of the Counties, Towns, Villages, Rivers, \&c., and Whatsoev- 


\section{Nancy Hall}

er is Usual in Geographies, and Minute Statistical Works; Together with a New Map of the State. Third edition. Washington City: P. Force.

Shores, David L. 2000. Tangier Island: Place, People, and Talk. Newark: University of Delaware Press.

Thomas, Charles Kenneth. 1936. Pronunciation in Upstate New York (VI). American Speech 11:307-313.

Tunley, Alison. 1999. Coarticulatory Influences of Liquids on Vowels in English. Ph.D. diss., University of Cambridge.

West, Paula. 1999a. The Extent of Coarticulation in English Liquids: an Acoustic and Articulatory Study. In Proceedings of International Congress of Phonetic Sciences 99. Vol. 3. 1901-1904.

West, Paula. 1999b. Perception of Distributed Coarticulatory Properties of English /1/ and /r/. Journal of Phonetics 27:405-426.

Yamada, Norio. 1983. A Constraint on Phonological Variables. Linguistic Analysis 12:29-84.

Nancy Hall

Department of Linguistics, PSY 114

California State University Long Beach

1250 Bellflower Boulevard

Long Beach, CA 90840-0902

hall.nancy@gmail.com 